\title{
FERNANDO GONZÁLEZ: DE LA VIDA AL CONCEPTO -VESTIGIOS FENOMENOLÓGICOS-1
}

\author{
Julio César Barrera Vélez ${ }^{2}$ \\ Universidad Santo Tomás
}

\section{Resumen}

Este estudio tiene por objeto presentar las convergencias entre algunos aspectos del método fenomenológico y los ejes filosóficos fundamentales del pensamiento de Fernando González.

\section{Palabras clave}

Filosofía, fenomenología, método, Fernando González.

\begin{abstract}
The aim of this study is not to show the influence of phenomenology in the works of Fernando González, nor what he could have taken form it, far from that its objective is to collect coincidences -even playing with the connotation of random situation carrying this word- that could exist between the thought basis of González and the foundations of the vision and the phenomenological method proposed by E. Husserl.
\end{abstract}

\section{Index terms}

Philosophy, phenomenology, method, Fernando González.

Ponencia presentada en el IV Congreso de pensamiento latinoamericano: "La construcción de América". Universidad de Nariño, 6-9 de octubre de 2004.

2 Profesor investigador de la Facultad de Filosofía y Letras de la Universidad Santo Tomás, Bogotá. Miembro del grupo Fray Bartolomé de las Casas, reconocido por Colciencias. Actualmente regenta el proyecto de investigación "Recepción de la fenomenología en Colombia”. 
A primera vista puede parecer insensato e ingenuo preguntase por las coincidencias que pueden existir entre la fenomenología, uno de los principales movimientos filosóficos del siglo XX, y el pensamiento de un escritor tropical cuya propia catalogación como filósofo es muy discutible; y aún parecerá más descabellado este propósito si se tiene en cuenta que Fernando González ${ }^{3}$ no conoció la fenomenología; y si leyó a Heidegger, lo hizo al final de su vida ${ }^{4}$. Como si eso fuera poco, este trabajo no se interesa por la fenomenología en su rama existencial (que fue la recorrida por Heidegger), sino por los desarrollos fenomenológicos de Husserl, los cuales, a su vez, tampoco llegaron a Colombia en la época de Fernando González. Por entonces escaseaban las traducciones al español de las obras de Husserl; su conocimiento se obternía a través de fuentes secundarias, a tal punto que uno de los primeros atisbos sobre fenomenología es una publicación de 1948, titulada Tres momentos de la fenomenología, de Adalberto Botero Escobar, que estudia a Husserl en los comentarios que de él hace Teodoro Celms (El idealismo de Husserl) ${ }^{5}$.

Por consiguiente, la intención de este estudio no es mostrar las influencias de la fenomenología en González ni lo que él pudo haber tomado de ella. Lejos de esto, su objetivo es recoger las coincidencias -jugando incluso con la connotación de azar y casualidad que comporta esta palabra-que podrían existir entre las bases del pensamiento de Fernando González y los fundamentos de la visión y el método fenomenológicos. No tendría sentido pretender que unas y otros concordaran enteramente, pero sí puede esperarse -y ésta es la hipótesis de trabajo-que haya puntos comunes en su manera de acercarse a la realidad, de plantearse problemas y de concebir la tarea de la filosofía (por eso, no pretendo hallar un desarrollo fenomenológico sistemático, sino simplemente indicios, o conatos de fenomenología). Tal concordancia es posible gracias a la formación autodidacta que insertó a González en las corrientes y tendencias de la filosofía europea contemporánea y le permitió participar de ese movimiento hacia lo concreto al que también corresponden los esfuerzos fenomenológicos y que nace de la desconfianza hacia todo apriorismo idealista.

En el fondo, este estudio no es más que un pretexto para acercarse al pensamiento de González con un recurso interpretativo de naturaleza flexible. Para ello es necesario comenzar con una exposición sucinta del pensamiento de Fernando González, luego ofrecer una visión general de los fundamentos de la fenomenología, y a partir de ella establecer los puntos de convergencia.

3 Fernando González nació en Envigado en 1895, se graduó como bachiller en filosofía y letras en 1917 y como doctor en derecho en 1919 en la Universidad de Antioquia. Se desempeñó como juez civil en Manizales y Medellín, y como cónsul en Génova, Marsella y Bilbao. Murió en Envigado en 1956. Produjo una bibliografía abundante que oscila entre la literatura, la sociología y la filosofía, sin que sea fácil definir a cuál pertenece. Su pensamiento intenta desligarse de la tradición escolástica imperante en las academias colombianas y ofrecer una mirada nueva de la realidad latinoamericana, siempre desde sus propias experiencias y con algún apoyo, no muy riguroso, en los filósofos europeos hasta entonces rechazados por el tradicionalismo colombiano.

4 En su última novela, Tragicomedia del padre Elías y Martina la velera, aparece una dedicatoria a Martin Heidegger. En una carta a Jaime Vélez Correa dice que Heidegger es el último cristiano que queda. Y aparece mencionado varias veces en el Libro de los viajes o de las presencias.

5 Para la recepción de la fenomenología en Colombia, cf. HERRERA, Daniel. América Latina y la fenomenología. México: Universidad Pontificia de México, 1998, pp. 7-29. 


\section{Pensamiento de Fernando González}

Sin pretender agotarlo, y sabiendo que es difícil sistematizar las posturas a veces contradictorias de González, se intentará presentar una visión general de su pensamiento mediante una síntesis temática que incluirá tres puntos: los problemas de que se ocupa, su noción de filosofía y sus métodos ${ }^{6}$.

\subsection{Problemas fundamentales}

Fernando González (FG) dedica la mayor parte de sus esfuerzos filosóficos a resolver tres problemas que lo afectan existencialmente. Dichos problemas, grosso modo, son:

1. La conciencia de límite ("Existo, luego soy limitado”), es decir, la conciencia de nuestra imposibilidad de ser infinitos, que nos diferencia de Dios y nos impide la comunión con el Universo. Al respecto nos dice FG: “¿Cómo no vivir triste al ser de un sólo modo? (...) La gran tristeza es la tristeza de ser limitado"7. Y agrega: "En el hombre hay un anhelo de infinito: el anhelo de poseerlo todo, de hacerse alma de las cosas" ${ }^{\text {. En respuesta a }}$ este problema surgirá la filosofía de la ensoñación, con la que pretende superar todos los límites por la intuición o sabiduría viva: "Yo disuelvo mi alma en el universo todo y así amo todo el univer-

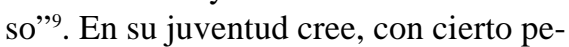
simismo, que tal disolución del espíritu en el infinito se logra por la ensoñación, al decirnos: “(...) y tu único consuelo ¡oh soñador! es soñar todas las visiones posibles" ${ }^{10}$.

Pero en los escritos de madurez encuentra la verdadera salida a la angustia del límite en el ejercicio de la filosofía como concienzación, esto es, como comprensión de las causas últimas de los fenómenos vivenciales.

2. El problema del vicio solitario. FG descubre que el problema de los latinoamericanos es que han sustituido la experiencia directa de la realidad por la perversión imaginativa. En este sentido acota en Don Mirócletes: "Entiendo por vicio solitario toda manera de efectuarse la descarga nerviosa que no sea excitada por la realidad. (...) El suramericano se habituó a que la masa nerviosa reaccionara con la imaginación y no con la realidad”"11. En contra de esta perversión del intelecto, afirma que la filosofía debe partir de las vivencias y redundar en una mayor conciencia de la propia vida. De otra manera, es un saber vano: pura filosofía en el vacío ${ }^{12}$. Con esta idea, que atraviesa todas sus obras, González revela su tendencia filosófica hacia lo concreto.

3. El problema del primer principio filosófico. El primer principio de la filosofía aristotélica es el de identidad o de no contradicción, según el cual "es imposible que el mismo atributo pertenezca y no pertenezca al mismo sujeto en un tiempo mismo y bajo la misma relación”13. Di-

\footnotetext{
6 Seguimos aquí la estructura propuesta en Alberto Restrepo, Para leer a Fernando González, Medellín: UPB, 1997. 
cho de otro modo, "no es posible que una misma cosa sea y no sea a un mismo tiempo" ${ }^{14}$. Pero este principio, justamente por ser el primero, no es demostrable, su veracidad debe suponerse: "No cabe demostración de este principio; y, sin embargo, se puede refutar al que lo niegue. En efecto, no hay otro principio más cierto que éste, del cual pudiera deducírsele por razonamiento, y era preciso que fuera así para que hubiera realmente demostración”"15. Para FG semejante condición resulta inaceptable de cara a la forma como se da la realidad a la conciencia cognoscente, así que niega el principio aristotélico.

A esto se añade que en la filosofía escolástica la enunciación del primer principio y la afirmación de la existencia de Dios ("El que es”) son una misma cosa ${ }^{16}$; por ende, negar el primer principio es negar a Dios. A este respecto dice FG en Los negroides: "Yo negué a Dios y el primer principio y desde ese día me estoy librando de lo que han vivido los hombres" ${ }^{17}$. En este acto hay una ruptura fundamental con la tradición filosófica occidental, que lo obligará a inventar un filosofar propio: la metafísica vivencial. En esta óptica, al decir del estudioso de la obra de González, Javier Henao Hidrón, el problema del primer principio persistió en FG hasta sus últimas obras, cuando, en el Libro de los viajes o de las presencias (1959), logra reformularlo, afirmando que "las cosas son y no son según las coordenadas”"18, es decir, sólo son en la medida en que aparecen en la conciencia de quien las experimenta.

\subsection{Noción de filosofía}

Del tratamiento de sus tres problemas fundamentales se deriva para FG una concepción peculiar de la filosofía: ella no es producto de la pura razón, sino expresión de estados de alma; es la búsqueda (vital, procesual y libre) de comunión con la Realidad - es decir, con el Ser, en términos clásicos- a partir de las manifestaciones de la realidad en la conciencia del yo limitado. Pero a tal comunión no se llega nunca plenamente, por lo cual la filosofía es una búsqueda interminable. En este sentido FG, en Cartas a Estanislao, nos dice que: "Jamás cesamos de filosofar; quien posee otra cosa que opiniones, conclusiones provisionales, es un demente” ${ }^{19}$. De igual forma en El hermafrodita dormido acota que "Quien afirma que ha poseído la verdad es (...) un viejo sofista" ${ }^{20}$.

La concepción de filosofía de FG se desarrolla en tres etapas. En la primera, durante su juventud, la concibe como ensoñación de mundos posibles. Así, en Pensamientos de un viejo dice: "Ésa es mi diversión. Soñar mundos. Filosofar, pues ¿qué otra cosa, sino aquello, es filosofar?" ${ }^{21}$. En otro pasaje de

Ibíd., XI, 5, p. 279.

Ibíd., XI, 5, p. 280.

16 Este principio es heredado de Parménides, quien afirma en su Poema del Ser que "lo mismo es el pensar y el ser [lit.: la misma cosa existe para el pensar y para el ser]”. KIRK, G. S. y J.E. Raven. Los filósofos presocráticos. Madrid: Gredos, 1969, p. 377. Citado por: MARTÍNEZ, Antoni y CORTÉS, Jordi. Diccionario de Filosofía. Barcelona: Herder, 1996.

17 GONZÁLEZ, Fernando. Los negroides. Medellín: Atlántida, 1936, p. 15.

18 GONZÁLEZ, Fernando. Libro de los viajes o de las presencias. $3^{\text {a }}$ ed. Medellín: UPB, 1995, p. 214.

19 GONZÁLEZ, Fernando. Cartas a Estanislao. 3ª ed., Medellín: UPB, 1997, p. 117.

20 GONZÁLEZ, Fernando. El hermafrodita dormido. $4^{a}$ ed. Medellín: UPB, 1994, p. 7.

21 GONZÁlEZ, Fernando. Pensamientos de un viejo. Op. Cit., p. 33. 
este mismo texto añade que “Toda filosofía no es otra cosa que los lloriqueos de los instintos no satisfechos. Más porque tiene muy grandes deseos, por eso se aleja el filósofo”22. La segunda etapa, que corresponde a la época de mayor producción intelectual, entiende la filosofía como reacción de la conciencia ante el devenir. Así, en El remordimiento dice: "La filosofía no es sino reacción escrita, hablada o vivida de la reactividad”23. En la misma línea alude al tema en Cartas a Estanislao al decir: "Este anidar sobre la vida y sus fenómenos ha sido mi profesión, y me ha causado tantas alegrías y penas que he llegado a llamar a la filosofía, mi mujer, mi amante"24. De esta manera, para Fernando González la filosofía se percibe también como una labor concientizadora. En Nociones de izquierdismo, acota al respecto que: "El papel del hombre en la tierra es bregar (arte, ciencias, trabajo) con lo cual se hace consciente o filósofo" ${ }^{25}$. La conciencia de las causas es unificadora; la filosofía se convierte en comprensión vital de causas y semejanzas, que unifica los hechos y libera de la multiplicidad fenoménica. Así, en Mi compadre dice: "Filosofemos un poco. Es lo único que nos liberta del variado fenómeno de la vida. Filosofamos para darle unidad a los hechos"26.

En su etapa final, ve la filosofía como liberación y comunión viva con Dios, pues es el medio para el nuevo nacimiento, la emancipación del determinismo causal y la vivencia de la reconciliación de los contrarios. Así lo explìcita en una carta al padre Jaime Vélez
Correa: "Filosofía es viajar en Dios, partiendo de nuestro yo original, concienzándonos y el viaje es infinito y de infinita beatitud. La filosofía es viva y es nutricia. El hombre nació para conocer y amar a Dios y ser beato en Él”27. En conclusión -provisional, para ser fiel a FG-, la filosofía es la búsqueda concienciadora del Ser en los fenómenos vivenciales.

\subsection{Método}

Según lo anterior, la función de la filosofía para FG es pasar del mundo contingente de las vivencias y los fenómenos, al mundo del Ser, fuente de toda manifestación. Expresa en las Cartas a Ripol, mediante una bella metáfora: "Venía yo por la carretera, atisbando a Dios en todas sus criaturas, que es la profesión mía”28. Para conseguirlo, construye un método dinámico-vivencial, es decir, que se basa en los movimientos del espíritu para llegar a la contemplación del Ser a partir de las manifestaciones de la vida en la conciencia. Su método, en cualquiera de las formulaciones que se encuentran de él, pasa por tres movimientos: 1) Vivencia fisiológi$c a$, pasional y emocional, en total desenfado y desfachatez, sin traba alguna, hasta su agotamiento, de la instintividad subconsciente. 2) Realización, con entera sinceridad, de los procesos reflexivos y analíticos del yo mental sobre las vivencias fisiológico- pasionales. 3) Ascensión activa, por el ascetismo de la disciplina y la contención, a la intuición de mundos suprafenoménicos, a la comunión con la Realidad o Dios. Este método, que FG

\footnotetext{
Ibíd., p. 176.

GONZÁLEZ, Fernando. El remordimiento. Op. Cit., p. 56.

GONZÁLEZ, Fernando. Cartas a Estanislao. Op. Cit., p. 116.

GONZÁLEZ, Fernando. Nociones de izquierdismo. Medellín: Universidad de Antioquia, 2000, p. 81.

GONZÁLEZ, Fernando. Mi compadre. 2a ed. Medellín: Bedout, 1973, p. 69.

GONZÁLEZ, Fernando. Fernando González visto por sí mismo. Edición facsimilar. Medellín: UPB, 1995, p. 24.

28 GONZÁLEZ, Fernando. Cartas a Ripol. 2a. ed. Bogotá: El Labrador, 1990, p. 28.
} 
construye a partir de su propia experiencia, es un proceso de convivencia integral con las manifestaciones de la vida en la conciencia, hasta desnudar la Realidad viva en ellas y unificarse. Al respecto, en Tragicomedia del Padre Elías y Martina la velera, dice: "Nada de eso que llaman 'método experimental', que no es más que imponerle cosas externas a nuestra mente. No, la convivencia va sucediendo, pero amistosamente, por entrega del ente: la tarea es, pues, unificarse con el ente" ${ }^{29}$. Debe advertirse que FG se refiere indistintamente al método en sentido filosófico, como camino para llegar a un conocimiento verdadero; y en sentido familiar, como camino de vida o guía para vivir de la mejor manera posible. Tal ambivalencia puede juzgarse como una falta de rigor, pero lo que hace patente es el primado de la vivencia de lo precategorial en su filosofar.

Entonces, a modo de recapitulación de este acápite sobre el filosofar de FG, afloran como rasgos de su pensamiento filosófico los siguientes aspectos: su inclinación a "buscar a Dios en las criaturas”, el desarrollo de su reflexión a partir de las propias vivencias, el reconocimiento de las emociones (los fenómenos de conciencia) como punto de partida del conocimiento filosófico, la función concienciadora y humanizadora que asigna a la filosofía, y el intento de acercarse a los fenómenos dejando de lado las apariencias y los juicios que otros les han superpuesto. A continuación se intentará señalar las coincidencias que puedan existir entre estos planteamientos y las ideas fundamentales del método fenomenológico, ejemplificándolas con la obra El remordimiento.

\section{Coincidencias del pensamiento de Fernando González con la fenomenología}

Es necesario comenzar este apartado con una referencia breve a los planteamientos fundamentales de la fenomenología (restringida aquí al método filosófico propuesto por Edmund Husserl). El ideal de la fenomenología es hacer de la filosofía una ciencia rigurosa, y para ello necesita un método que le permita operar con certeza, sin admitir ningún juicio que no sea evidente. Esto exige, en primer lugar, dudar de que los objetos en el mundo sean cognoscibles tal como son, e incluso, de que existan realmente en el mundo. Suponemos que son así, pero lo único que podemos saber con evidencia es que se nos presentan así, están dados como fenómenos en nuestra conciencia. Por eso la fenomenología no se ocupa de los objetos en cuanto a que puedan existir en el mundo sino de su existencia fenoménica realmente dada en nuestra conciencia ${ }^{30}$. El proceso que se sigue para llegar al objeto y describirlo tal como nos es dado, requiere:

Una triple eliminación o “reducción”, llamada “epoché”: primeramente de todo lo subjetivo: la postura ante el objeto debe ser puramente objetiva; en segundo término, exclusión de todo lo teórico (hipótesis, demostraciones u otra cualquier forma de saber ya adquirido), de manera que tan sólo entre en cuestión lo dado; y en tercer lugar, exclusión de toda tradición, es decir, de todo aquello que se ha venido enseñando hasta el presente so-

29 GONZÁLEZ, Fernando. Tragicomedia del padre Elías y Martina la velera. 3a. ed. Medellín: UPB, 1996, p. 51.

30 Cf. HUSSERL, Edmund. Pure phenomenology, Its method and Its field of investigation (Lectio inauguralis en la Universidad de Friburgo, 1917). <http:/www.baylor.edu/`Scott_Moore/essays/Husserl.html>. 
bre el objeto. En el mismo objeto dado todavía hay que llevar a cabo una doble reducción: hay que dejar de lado la consideración de la existencia de la cosa y centrar la atención exclusivamente en torno a la quididad, a lo que el objeto es; $\mathrm{y}$, después, hay que separar de esta quididad todo lo accesorio y analizar sólo la esencia de la cosa ${ }^{31}$.

En el método fenomenológico, pues, se trata de captar el fenómeno en su totalidad y de describir todos sus componentes del modo más exhaustivo posible, pues el objetivo es obtener su esencia, es decir, la estructura fundamental del fenómeno ${ }^{32}$. A esto hace alusión el lema de la fenomenología: ir "a las cosas mismas” ( $\mathrm{Zu}$ den Sachen selbst). El rigor de la fenomenología radica en ceñirse a los fenómenos, sin permitirse caer en la actitud natural que cree poder conocer objetivamente. El fenomenólogo suspende la idea de que el sentido del mundo está en el mundo mismo y reconoce, en cambio, que es el sujeto mismo, gracias a su experiencia subjetiva de ese mundo, su mundo de la vida, el que le confiere un sentido ${ }^{33}$. Por eso el fenomenólogo confía sólo en la visión reflexiva, por la cual la conciencia (y la cosa de la que se tiene conciencia) es aprehendida de modo absoluto, en una experiencia directa, ya que ningún fenómeno de la conciencia es exterior a ella. Pues, al decir de Husserl,
"Es como si el mundo objetivo hubiera sido puesto entre paréntesis. Lo que nos queda es la totalidad de los fenómenos del mundo, fenómenos que aprehendemos por reflexión tal como ellos son absolutamente en sí mismos [in ihrer absoluten Selbstheit]"34.

Ahora bien, en este doble panorama, del pensamiento de FG y de la fenomenología, saltan a la vista coincidencias importantes. En primer lugar, coinciden en el punto de partida del filosofar: el mundo de la vida, es decir, el horizonte de las propias vivencias. FG se niega a ser un filósofo en el vacío; por eso no puede desligar su filosofar de los acontecimientos vivenciales. Desde su juventud adquirió la costumbre de anotar en libretas ("unos cuadernitos de esos que usan los carniceros para apuntar los fiados”) $)^{35}$ sus experiencias cotidianas, así como los sentimientos e ideas suscitados por ellas. Tales libretas constituyen el origen de gran parte de sus libros, en los que despliega la reflexión filosófica a partir esos registros de sus observaciones vivenciales. He aquí algunos fragmentos de sus libretas de 1934, que titula su autor "la semilla de donde salió El remordimiento", texto que he seleccionado para evidenciar las coincidencias ${ }^{36}$.

14 DE MARZo - He caminado todo el día. Veo a la muerte en las mujeres, tan hermosas, y en los árboles que se renuevan. No me agrada la alegría.

31 Cf. GÓMEZ ROMERO, Isidero. Husserl y la crisis de la razón. Madrid: Cincel. 1986.

32 Cf. Ibíd., pp. 57-59.

33 VARGAS, Germán. La fenomenología ante la inteligencia artificial: en la búsqueda de los límites de la subjetividad. Conferencia dictada en la Universidad Santo Tomás de Bogotá, en julio de 2000.

34 HUSSERL, Edmund. Op. Cit.

35 GONZÁLEZ, Fernando. El maestro de escuela. Bogotá: Norma, 1998, p. 54.

36 En él Fernando González presenta una disertación moral acerca del comportamiento humano, del deseo, la tentación, el remordimiento, el arrepentimiento y la confesión, y de la lucha por perfeccionarse en la virtud. Toda esta reflexión surge de sus remordimientos por no haber aprovechado el amor que le ofrecía Tony, la hermosa niñera de sus hijos en Marsella. Escribe este libro para "sacar en limpio, comentar y terminar las notas escritas durante la época en que vivió en casa la señorita Tony”. GONZÁLEZ, Fernando. El remordimiento. Op. Cit., p. 16. 
Voy a observar el llegar de la primavera.

15 DE MARZo - Ayer las mujeres estaban bellas, casi, casi sin ropa de lana. ¡Hasta las viejas estaban hermosas! Seca la piel, rosadas, ágiles. En Plaza Castellana vi una, jorobada, y estaba hasta muy bella.

Pero todos andan alocados por la primavera, como preguntando con sus actitudes y miradas: ¿dónde arrojo esta alegría? Se percibe, pues, la muerte.

17 DE MARZo - (...) Sensaciones-imágenes que me suben: Tony tiene los pechos erectados, puntudos y separados; hieren la tela de la blusa.

Tiene los ojos afelpados. Está como [mi gata] Salomé.

¡Sólo Dios! ¡Sólo la idea de belleza! Lo que tenemos aquí es lejanísimos amagos de lo agradable, que nos vienen de más lejos que la luz de los soles que gastan mil años para aparecer aquí como ojos de gato en la oscuridad ${ }^{37}$.

A partir de estos fenómenos vivenciales, González se da a la tarea de captar la verdad de la vida, y ello implica encontrar la lógica de los instintos vitales; no negarlos, sino, al contrario, describir su experiencia plena. Por eso en el texto en cuestión dice: "De nuestros amores nacieron el remordimiento y algunas consideraciones"38. El origen del filosofar está, pues, en una situación vivencial o, en términos fenomenológicos, en una experiencia particular del mundo de la vida.

La segunda coincidencia está en que para ambas filosofías la reflexión se hace sobre los fenómenos, es decir sobre la manifesta- ción de las experiencias en la conciencia, mediante la descripción precisa de sensaciones, recuerdos e impresiones. A González no le interesa escribir una autobiografía en la que se coleccionen los hechos como vistos por un observador exterior; en cambio, tematiza lo que siente frente a esos hechos, lo que recuerda, lo que percibió y tal como fue percibido. Se ocupa del fenómeno del remordimiento, que es el remanente dejado en su conciencia por aquello que vivió con Tony. Estudiar el remordimiento para González implica “volver sobre los amagos de actos”39 (las intenciones), que sólo pueden encontrarse en la conciencia. Esta condición fenoménica de su reflexión filosófica produce una característica peculiar del pensamiento de González, a saber: sus conceptos son emocionales e intelectuales a la vez, es decir que en la construcción del concepto se incluye un fundamento sensible sobre el cual se erige luego una estructura racional. Por ejemplo, el concepto de remordimiento (que define como "la intranquilidad que precede, acompaña o sigue a una acción” cuando es reprobada por una tendencia juzgada por el yo o resultante superior a la incitadora $)^{40}$ es el resultado de la descripción exhaustiva de una sensación que obsesiona al autor. Al comienzo del libro citado dice: "En Envigado tengo un remordimiento de no haberme acostado con Tony que me está matando”. "Mi carne me grita: ‘¿Por qué no te acostaste con Tony?’’41. Así se hace evidente que la racionalidad de González es inseparable de sus sentimientos: piensa sensiblemente, o siente racionalmente; ambas instancias constituyen una unidad (habría que preguntarse si tal racionalidad sensible es compatible con el filosofar occidental).

\footnotetext{
37 Ibíd., pp. 119, 120 y 124.

38 Ibíd., p. 15.

39 Ibíd., p. 18.

40 Ibíd., p. 80.

${ }^{41}$ Ibíd., p. 18.
} 
En tercer lugar, encontramos que, en cierto sentido, puede equipararse el objetivo del filosofar en la fenomenología con el del pensamiento de González. Para ambos, al final del proceso filosófico debe hallarse aquello que hay de invariable en los fenómenos, su ser; este será un saber que escape de la contingencia y que nos acerque al hombre infinitamente lejano, a Dios. La función de este filosofar es ascender en conciencia; por tanto, es una práctica que debe humanizar al filósofo. Suena extraño, pero en el pensamiento de FG hay una unificación de los fines filosóficos universales con los de perfeccionamiento personal. La conciencia es el fruto de la vida filosófica. Tal vez por esto nos dice que "Aceptaría diez mil años de experimentación para ascender en conciencia" ${ }^{42}$. La vida es, para él, "campo de experimentación y ascenso"; por eso "Tenemos el derecho de gozar de todos los instintos, para sentir el dolor que causa el goce y llegar así, poco a poco, a la beatitud. Ésta consiste en estado de conciencia no sujeto al tiempo ni al espacio" $^{43}$. De esta forma, el filosofar le permite liberarse de la contingencia de los fenómenos y penetrar en el ser, pues "El ser está fuera de la apariencia: Esto es evidente. Dios no existe. Es. Yo soy el que es”44.

Queda, de este modo, expuesta una hipótesis de interpretación del pensamiento de Fernando González. Es evidente que los puntos comunes entre la fenomenología y esta otra filosofía, quizás demasiado local, no son producto de desarrollos conceptuales intencionales; pero sí tendría sentido señalarlos como una muestra de la inserción real de González en la nueva tradición filosófica de Occidente, al participar de ese movimiento hacia lo concreto, de ese regreso al mundo de la vida, y al presentarnos a nosotros, filósofos del presente, esta exigencia ineludible de vincular la filosofía a la propia existencia.

Ibíd., p. 20.

${ }^{43}$ Ibíd., p. 25.

44 Ibídem. 